\title{
Influence of Microsprinkler Irrigation Amount on Water, Soil, and pH Profiles in a Coastal Saline Soil
}

\author{
Linlin Chu, ${ }^{1,2}$ Yaohu Kang, ${ }^{2}$ and Shuqin Wan ${ }^{2}$ \\ ${ }^{1}$ National Research Center of Pumps, Jiangsu University, Zhenjiang 212013, China \\ ${ }^{2}$ Key Laboratory of Water Cycle and Related Land Surface Processes, Institute of Geographic Science and Natural Resources Research, \\ Chinese Academy of Sciences, Beijing 100101, China
}

Correspondence should be addressed to Yaohu Kang; kangyh@igsnrr.ac.cn

Received 13 March 2014; Revised 10 June 2014; Accepted 8 July 2014; Published 23 July 2014

Academic Editor: Antonio Paz González

Copyright (C) 2014 Linlin Chu et al. This is an open access article distributed under the Creative Commons Attribution License, which permits unrestricted use, distribution, and reproduction in any medium, provided the original work is properly cited.

\begin{abstract}
Microsprinkler irrigation is a potential method to alleviate soil salinization. After conducting a homogeneous, highly saline, clayey, and coastal soil from the Bohai Gulf in northern China in a column experiment, the results show that the depth of the wetting front increased as the water amount applied increased, low-salinity and low-SAR enlarged after irrigation and water redistribution, and the soil $\mathrm{pH}$ increased with an increase in irrigation amount. We concluded that a water amount of $207 \mathrm{~mm}$ could be used to reclaim the coastal saline soil in northern China.
\end{abstract}

\section{Introduction}

The coastal land surrounding Bohai Gulf in northern China is a resource constrained by population growth, rapid industrialization, and agricultural production [1-3]. The soils developed from highly saline coastal mud flats consist of highly saline upper and lower soil horizons, with salinity similar to that of seawater [4]. The shallow groundwater system is also saline, with an electrical conductivity (ECe) between 4.9 and $20.5 \mathrm{dS} / \mathrm{m}[3,5]$. In addition, strong evaporation increases the rise of salts through the soil profile to the surface. These costal soils are characterized by heavy texture, high content of exchangeable sodium, poor structure, and low water permeability. As a result, the soil does not support vegetation, except for salt resistant halophytes. Therefore, urgent measures are required to alleviate soil salinization and to enable utilization of the saline land.

Several methods have been used to reclaim coastal saline soils including ponding irrigation, chemical amendment, biological reduction, and the replacement of the entire surface soil with nonsaline soil [4, 6-9]. However, these methods are not practical for the coastal land of Bohai Gulf due to the scarcity of freshwater resources and to the low hydraulic conductivities of the soil near saturation. Moreover, when saturated soil conditions persist, growth and production may be inhibited $[10,11]$. Chemical amelioration is costly, and developing countries only provide marginal assistance to local farmers for soil amendments. Biological methods for the reduction of salts cannot ameliorate coastal saline soils for long periods of time, and this would be also the case if the entire soil surface would be replaced with a higher quality soil [12-14]. Therefore, there is a need for usable, cheap, and simple methods for combating soil salinization and reclaiming saline land.

Efficient irrigation methods such as drip irrigation, sprinkler irrigation, and microsprinkler irrigation allow precise quantification and positioning of water and chemicals within the soil profile. These methods are considered advantageous due to their high water-use efficiency and their ability to displace salt under unsaturated flow conditions. We have conducted several studies on the efficiency of different dripirrigation rates for reclaiming coastal saline soils, and we succeeded in the design of adequate reclamation $[3,15]$.

Sprinkler irrigation, which has some similitude to natural rainfall, has been used to ameliorate saline soils under continuously unsaturated conditions [16, 17]. Nonetheless, the kinetic energy of sprinkler droplets can impact the soil surface, destroy soil aggregates, decrease infiltration rate, and 
promote leaching. These effects are exacerbated by longer irrigation times and higher irrigation rates [18].

Microsprinkler irrigation has been demonstrated as beneficial for tree and vine crops, because it can promote growth, improve yields, decrease water, and decrease energy use compared to sprinkler or flood irrigation systems, and protects plants from adverse climatic conditions much more than drip irrigation [19]. Microsprinkler irrigation has been examined with a focus on water-use efficiency, crop growth, and system layout, but no studies have focused on the depth distributions of the soil water content $(\theta)$ and salinity. Drip irrigation is now considered a potential effective method to reclaim the coastal saline soils, but whether microsprinkler irrigation can more efficiently displace salt and more accurately deliver water volumes still remain open questions.

Based on the above rationale, the objectives of this research were to determine the depth distributions of soil water content $(\theta)$, electrical conductivity (ECe), sodium adsorption ratio (SAR), and $\mathrm{pH}$ of saturated soil extracts after application of different water amounts from microsprinklers.

\section{Materials and Methods}

2.1. Study Site, Soil Sampling, and Preparation. Soil samples were collected from the Caofeidian Development Zone $\left(39^{\circ} 12^{\prime} \mathrm{N} ; 118^{\circ} 31^{\prime} \mathrm{E}\right)$ in Tangshan Bay Eco-city, east of Hebei province and west of Bohai Gulf. The region has a semihumid marine climate, with a mean annual temperature of $11.4^{\circ} \mathrm{C}$ and a mean annual precipitation of $554.9 \mathrm{~mm}$, with $74 \%$ of the precipitation occurring between June and September. Bulk density, ECe, and $\mathrm{pH}$ of the initial soil for each soil layer are shown in Table 1 . The average ECe and $\mathrm{pH}$ were $29.6 \mathrm{dS} / \mathrm{m}$ and 7.4, respectively. In addition to the high ECe, the saturated hydraulic conductivity of the soil $(0.0025 \mathrm{~mm} / \mathrm{d})$ was very low in fields irrigated with nonsaline water due to soil dispersion and clogging of soil pores.

Soil samples were collected from the A-horizon and were air-dried, crushed, passed through a $2 \mathrm{~mm}$ sieve, and characterized for general properties. The ECe, SAR, and $\mathrm{pH}$ of the homogenous soils were $27.8 \mathrm{dS} / \mathrm{m}, 59.7(\mathrm{mmol} / \mathrm{L})^{0.5}$, and 7.6 , respectively. The study soil was classified as a Solonchak and it was silt loam textured, with $0.49 \%$ of particles less than $0.002 \mathrm{~mm}, 45.14 \%$ of particles between 0.002 and $0.02 \mathrm{~mm}$, and $54.37 \%$ of particles larger than $0.02 \mathrm{~mm}$.

2.2. Laboratory Experiment. Columns to contain the soil were made of acrylic glass with a diameter and height of $110 \mathrm{~mm}$ and $600 \mathrm{~mm}$, respectively, and drainage holes at their base for percolating water (Figure 1(a)). Each soil column was filled with air-dried saline soil to attain $1.5 \mathrm{~g} / \mathrm{cm}^{3}$, the bulk density of the original soil at the experimental site. The initial soil water content of the experimental columns was $4 \mathrm{gr} / 100$. The soil in the columns was homogeneous and assumed to have vertical water flow throughout the experiment. To reduce the impact of airflow and evaporation, the experiment was conducted in laboratory conditions.

The columns were irrigated using fresh water with an ECe of $0.4 \mathrm{dS} / \mathrm{m}$ and a $\mathrm{pH}$ of 8.6 via a small plastic swivel microsprinkler (RC-40, Luckrain Irrigation Company,
TABLE 1: Bulk density, electrical conductivity of saturated paste extracts (ECe), and $\mathrm{pH}$ of the initial soil profile sampled at Caofeidian Eco-city, Hebei, China.

\begin{tabular}{lccc}
\hline Depth $(\mathrm{cm})$ & Bulk density $\left(\mathrm{g} / \mathrm{cm}^{3}\right)$ & ECe $(\mathrm{dS} / \mathrm{m})$ & $\mathrm{pH}$ \\
\hline $0-10$ & 1.32 & 30.6 & 7.2 \\
$10-20$ & 1.51 & 29.4 & 7.3 \\
$20-30$ & 1.58 & 28.8 & 7.6 \\
$30-40$ & 1.71 & 28.6 & 7.7 \\
$40-60$ & 1.62 & 28.9 & 7.5 \\
$60-80$ & 1.79 & 29.6 & 7.3 \\
$80-100$ & 1.62 & 30.9 & 7.1 \\
$100-120$ & 1.62 & 30.1 & 7.1 \\
\hline Average & 1.60 & 29.6 & 7.4 \\
\hline
\end{tabular}

Beijing, China) with a single nozzle, a height of $65 \mathrm{~cm}$, and a wetting radius of $2.5 \mathrm{~m}$. The nozzle operating pressure was maintained at $0.2 \mathrm{MPa}$ using a hydraulic-pressure control valve. The soil columns were all arranged $2 \mathrm{~mm}$ apart in a concentric circle with a $2 \mathrm{~m}$ radius, and the microsprinkler was positioned at the center (Figure 1(b)). When a column received the designated quantity of water, it was covered immediately with plastic film. Five water amounts $(55,128$, 185,207 , and $223 \mathrm{~mm}$ ) were applied, and each irrigation treatment was repeated three times. The mean air temperature during irrigation was $25^{\circ} \mathrm{C}$, and each treatment was irrigated at a rate of $1.2 \mathrm{~mm} / \mathrm{h}$.

\subsection{Measurements of Irrigation Dose and Soil Properties}

2.3.1. Irrigation Amounts. The amount of water delivered by the microsprinkler was measured using a conical flask positioned at the same distance from the microsprinkler as the soil columns (Figure 1(c)). After each irrigation event, the quantity of water in each triangular flask was evaluated according to the following:

$$
\mathrm{IA}=\frac{m_{2}-m_{1}}{\rho_{w} \times \pi \times r^{2}} \times 10,
$$

where IA is the irrigation amount $(\mathrm{mm}) ; m_{1}$ and $m_{1}$ are the quantities of water in the conical flask before and after irrigation was finished, respectively $(\mathrm{g}) ; \rho_{w}$ is the water density $\left(\mathrm{g} / \mathrm{cm}^{3}\right)$; and $r$ is the inlet radius of the triangular flask (cm).

2.3.2. Soil Water Content and Salinity. Soil samples for each treatment were extracted vertically from the soil column with an auger $(3.0 \mathrm{~cm}$ diameter and $100 \mathrm{~cm}$ height). Samples were taken during the redistribution period at 0,24 , and $48 \mathrm{~h}$ after application of the prescribed water amount was finished (Figure 1(c)). The distance between adjacent vertical samples was set to $1.7 \mathrm{~cm}$ (Figure 1(d)). After a full vertical sample was obtained for each period, plastic cloth was placed over the hole to avoid a dehydrating influence of successive samplings. The sample depths were $0-5,5-10,10-15,15-20,20-25,25-30$, 


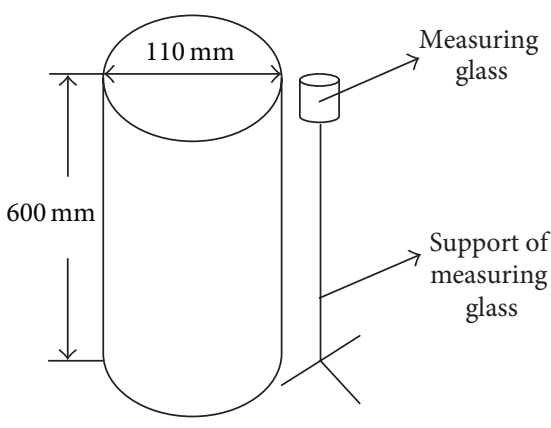

(a) Sketch of soil column and conical flask (measuring glass)

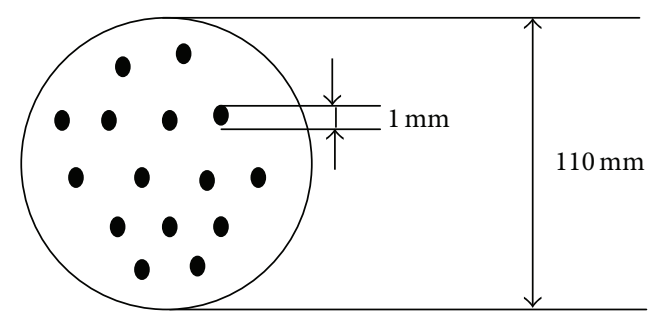

(b) The bottom holes of a soil column

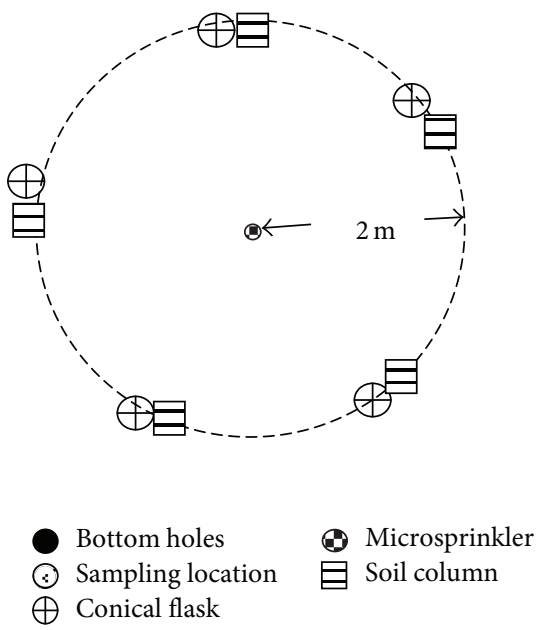

(d) Soil columns and measuring glasses position relative to microsprinkler for different water amounts applied

FIGURE 1: Sketch of the experimental setup showing the location of microsprinkler, soil columns, and measuring glasses, with details of bottom holes and sampling location within a column.

$30-35,35-40,40-45,45-50,50-55$, and $55-60 \mathrm{~cm}$. The water content $(\theta)$ was determined by oven-drying on a subsample.

For each sampling depth, the remaining soil samples were air-dried and sieved through a $2 \mathrm{~mm}$ sieve. A saturated soil paste was prepared via centrifugation $(4000 \mathrm{rpm}, 20 \mathrm{~min})$ for chemical analysis. The soil ECe, soluble cations $\left(\mathrm{Na}^{+}\right.$, $\mathrm{Ca}^{2+}$, and $\mathrm{Mg}^{2+}$ ), and $\mathrm{pH}$ were determined in extracts of the saturated soil, and the results were determined using a conductivity meter (DDS-11, REX, Shanghai), inductively coupled plasma optical-emission spectrometer (Optima 5300DV, PerkinElmer, U.S.A), and a pH meter (PHS-3C, REX), respectively. The SAR of the saturated paste extract was calculated using the following:

$$
\mathrm{SAR}=\frac{\left[\mathrm{Na}^{+}\right]}{\left(\left[\mathrm{Ca}^{2+}\right]+\left[\mathrm{Mg}^{2+}\right]\right)^{0.5}}
$$

where the concentration of each cation is in $\mathrm{mmol} / \mathrm{L}$.

The average $\theta, \mathrm{ECe}, \mathrm{SAR}$, and $\mathrm{pH}$ of the wet zone were calculated as the weighted mean.

2.3.3. Statistical Analysis. Statistical analyses, including a one-way analysis of variance (ANOVA), were conducted to compare and rank the treatment means at the $5 \%$ probability level for $\theta, \mathrm{ECe}, \mathrm{pH}$, and periods of soil water redistribution. Statistical analyses were performed using SPSS Version 16.0.

\section{Results and Discussion}

3.1. Wetting Front. When the irrigation time increased from $47 \mathrm{~h}$ to $189 \mathrm{~h}$, the irrigation amount increased from $55 \mathrm{~mm}$ to $223 \mathrm{~mm}$. This corresponded to a vertical wetting front, just after irrigation has been completed (at $0 \mathrm{~h}$ ), of 15-20, $40-45,55-60,55-60$, and $55-60 \mathrm{~cm}$, for each successive irrigation amount. These results showed that as the irrigation amount increased, also the depth of the wetting front at $0 \mathrm{~h}$ increased (Table 2). Moreover, the vertical wetting front was not significantly different among 0,24 , and $48 \mathrm{~h}$ since irrigation has ceased.

3.2. Soil Water Content $(\theta)$. The depth distributions of $\theta$ at 0,24 , and $48 \mathrm{~h}$ since irrigation has finished under different irrigation amounts are presented in Figure 2. It is generally accepted that during infiltration $\theta$ will decrease with increasing soil depth and a relatively moist region forms in the upper 
TABLE 2: Period of irrigation and depth of the wetting front at 0,24 , and $48 \mathrm{~h}$ during redistribution for each irrigation amount.

\begin{tabular}{lcccc}
\hline Irrigation amounts $(\mathrm{mm})$ & Irrigation hours $(\mathrm{h})$ & \multicolumn{3}{c}{$\begin{array}{c}\text { Depth of the wetting front }(\mathrm{cm}) \\
\text { 24 h of water redistribution }\end{array}$} \\
\hline 55 & 47 & $15-20$ & $15-20$ & $15-20$ \\
128 & 108 & $40-45$ & $45-50$ & $45-50$ \\
185 & 156 & $55-60$ & $55-60$ & $55-60$ \\
207 & 175 & $55-60$ & $55-60$ & $55-60$ \\
223 & 189 & $55-60$ & $55-60$ & $55-60$ \\
\hline
\end{tabular}

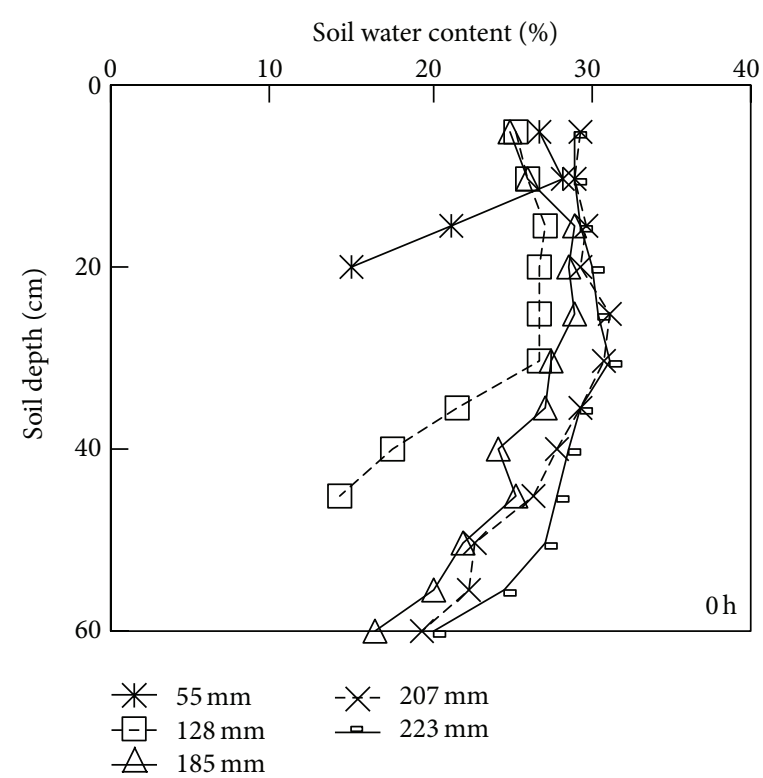

(a)

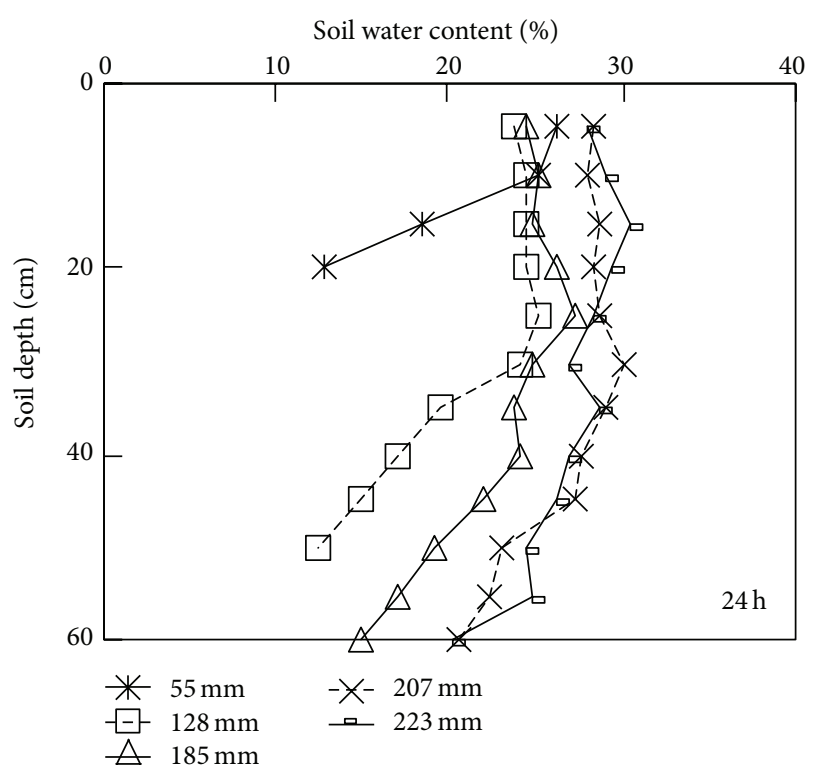

(b)

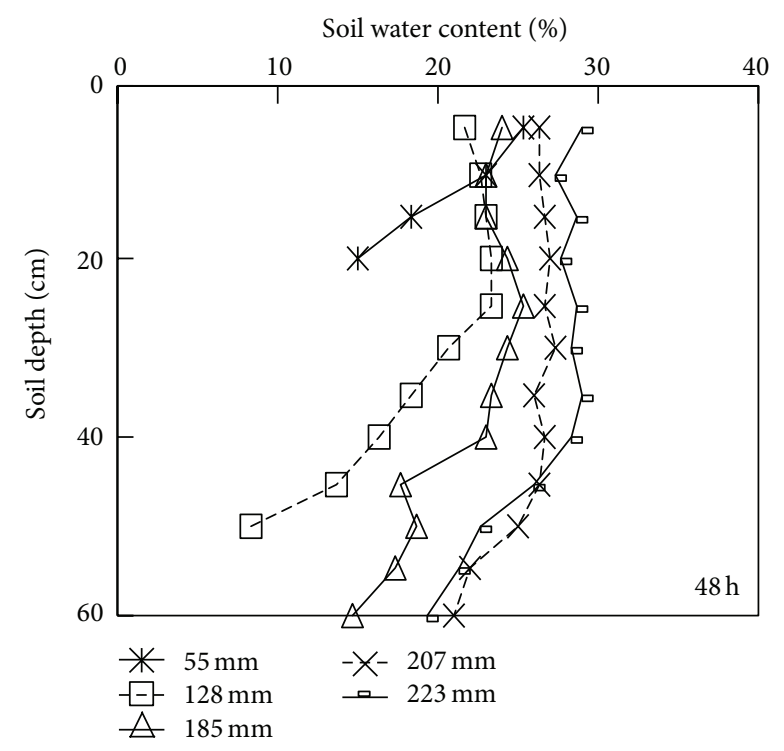

(c)

FIGURE 2: The depth distributions of soil water content at 0 hour (a), 24 hours (b), and 48 hours (c) during water redistribution under different water amounts applied. 
layer, where in turn a saturated zone and a transmission zone may be recognized. In our experiment, only a small amount of soil water moved toward the deep layer of the soil column, due to the low hydraulic conductivity of the heavy textured soil studied. Therefore, just after irrigation $(0 \mathrm{~h}), \theta$ was greater at $0-20 \mathrm{~cm}$ depth than at $20-40$ and $40-60 \mathrm{~cm}$ for all the studied treatments.

For all the treatments, the water content $(\theta)$ at the wet upper layer (involving saturation and transmission zones) was uniform and approached the maximum $\theta$ content. The maximum $\theta$ values for the irrigation amounts of $55,128,185$, 207 , and $223 \mathrm{~mm}$ were $28.3 \%, 26.9 \%, 28.8 \%, 31.1 \%$, and $31.0 \%$, respectively, and were measured at depths of 5-10, 10-15, 10$15,20-25$, and $25-30 \mathrm{~cm}$, respectively. Therefore, as the total irrigation amount was the highest, the depth of the wet zone increased. Furthermore, the average $\theta$ value of the wet zone showed a trend to increase as the irrigation amount increased. For example, the average $\theta$ in the wet zone increased from $22.8 \%(55 \mathrm{~mm})$ to $29.4 \%(223 \mathrm{~mm})$, and the vertical extent of this zone also increased, which is in accordance with the results of Troiano et al. [20].

As expected, during the redistribution of soil moisture, the matric potential of the soil water showed a trend to approach equilibrium, and consequently the depth differences in $\theta$ decreased. Compared to the results obtained at $0 \mathrm{~h}$, the water content $(\theta)$ measured at each depth decreased at $24 \mathrm{~h}$ and $48 \mathrm{~h}$ after irrigation has ceased. The mean $\theta$ values of the wet zones decreased by $10.9 \%, 19.0 \%, 13.5 \%, 5.9 \%$, and $5.9 \%$ for the irrigation amount of $55,128,185,207$, and $223 \mathrm{~mm}$, respectively. Overall, the observed reduction in $\theta$ decreased with an increase in irrigation amount. During soilwater redistribution events, the air in the soil pore space was replaced by water.

\subsection{Soil Salinity}

3.3.1. Depth Distributions of ECe. A consequence of the lateral and vertical movement of water, and the line-source nature of microsprinkler irrigation, is that salts and water are moving toward the subsoil forming a desalinized region at the saturated and transmission zones, and subsequently salts can accumulate near to the wetting front. The profiles of the ECe at 0,24 , and $48 \mathrm{~h}$ during water redistribution under different irrigation doses are shown in Figure 3 . At $0 \mathrm{~h}$, just after irrigation has ceased, as the irrigation amount increased, also the depth of the layer with low salinity $(\mathrm{ECe}<4 \mathrm{dS} / \mathrm{m})$ increased; this layer extended at $0-5,0-10,0-20,0-20$, and $0-$ $25 \mathrm{~cm}$ for irrigation amounts of 55, 128, 185, 207, and $223 \mathrm{~mm}$, respectively. Besides, the maximum ECe value of the column was significantly higher than the initial value, going up to $38.5,38.6,38.7,30.2$, and $32.1 \mathrm{dS} / \mathrm{m}$ for irrigation amounts of 55, 128, 185, 207, and $223 \mathrm{~mm}$, respectively. Furthermore, the maximum ECe was observed at a depth of 15-20, 35$40,50-55,50-55$, and $50-55 \mathrm{~cm}$, for the successive irrigation doses applied. Thus, as the irrigation amount increased, the thickness of the desalinized upper layer increased, while the salt concentration reached a maximum at the middle and lower layers of the column.
During the water redistribution phase, at $48 \mathrm{~h}$, for the irrigation amount of $55 \mathrm{~mm}$, the average ECe decreased as water redistribution progressed, and a $33.8 \%$ reduction in ECe was measured at $0-20 \mathrm{~cm}$ depth at the $48 \mathrm{~h}$ sampling, during water redistribution. Reductions of average ECe for the other four irrigation amounts were not significant, but the desalinization rate of the irrigation amount of $55 \mathrm{~mm}$ was significantly lower than those of the other treatments.

3.3.2. Relationship between the Average ECe Value and Irrigation Amount. The relationships between average ECe values in the wetting zone, at successive times during redistribution, and the irrigation amount (IA) can be expressed by the following equation:

average $\mathrm{ECe}_{0}$

$$
=-0.0005(\mathrm{IA})^{2}+0.0614(\mathrm{IA})+20.489 \quad R^{2}=0.8853,
$$

average $\mathrm{ECe}_{24}$

$$
=-0.0006(\mathrm{IA})^{2}+0.101(\mathrm{IA})+15.99 \quad R^{2}=0.9614,
$$

average $\mathrm{ECe}_{48}$

$$
=-0.0005(\mathrm{IA})^{2}+0.1103(\mathrm{IA})+13.838 \quad R^{2}=0.9216 .
$$

The above relationships show that during redistribution, ECe and irrigation dose could be fitted by parabolic equations with high $R^{2}$ values (Figure 4). Compared to the initial results $0 \mathrm{~h}$ after water redistribution, the average ECe values for the wetting zones of irrigation amounts of 55, 128, 185, 207, and $223 \mathrm{~mm}$ were decreased by $17.6 \%, 31.9 \%, 32.8 \%, 52.4 \%$, and $63.7 \%$, respectively. When the irrigation amount increased from 55 to $223 \mathrm{~mm}$, the average soil ECe in the wet zone decreased by $55.9 \%$ (from 22.9 to $10.1 \mathrm{dS} / \mathrm{m}$ ).

As the irrigation amount decreased, the average ECe at a depth of $0-20 \mathrm{~cm}$ increased by $17.6 \%, 81.1 \%, 91.6 \%, 92.3 \%$, and $94.4 \%$, compared to the initial ECe value. All of the salts were leached down to deeper levels in each irrigation amount, especially for irrigation amounts of 207 and $223 \mathrm{~mm}$. However, the observed differences in the profiles of soil moisture and ECe values among the irrigation amounts of 207 and $223 \mathrm{~mm}$ were low during water redistribution. Therefore, a significant change in the average ECe value was not observed as the irrigation amount increased from $207 \mathrm{~mm}$ to $223 \mathrm{~mm}$. Meanwhile, the ANOVA results showed that the average ECe for all of the irrigation amounts were significant $(P<0.05)$.

3.4. Depth Distribution of SAR. The sodium adsorption ratio, SAR, is well known to be related to soil dispensability. In practice, SAR and electrical conductivity values of irrigation water allow assessment of its potential to promote soil dispersion. The depth distributions of SAR at $0 \mathrm{~h}$ after water application had ceased under the different irrigation amounts are shown in Figure 5. The observed changes in the SAR with successive irrigation doses were similar to those of the ECe values. At the end of the experiment, the SAR of all 


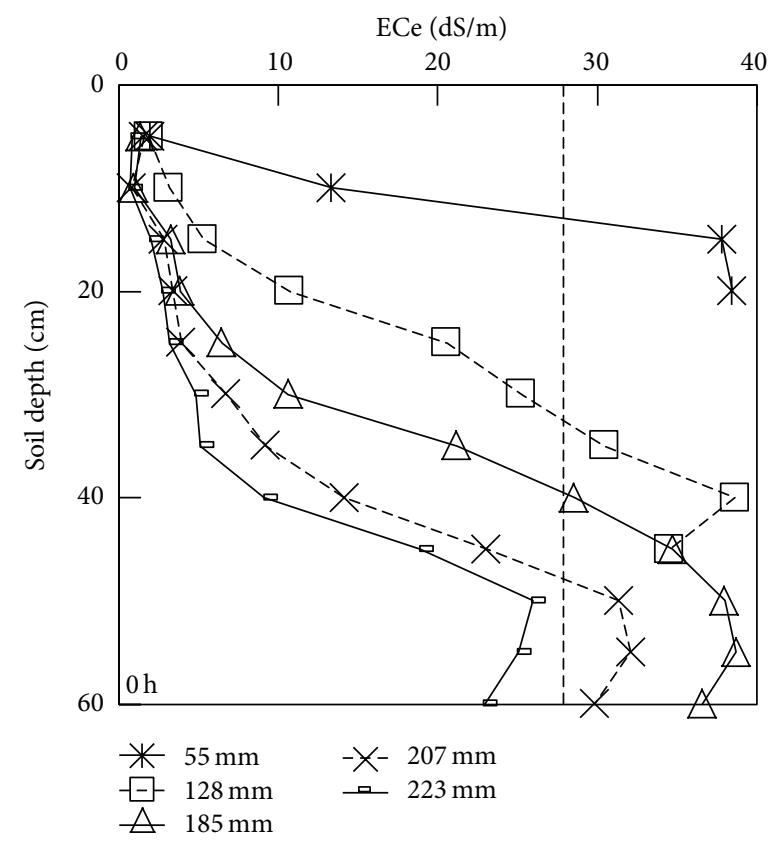

(a)

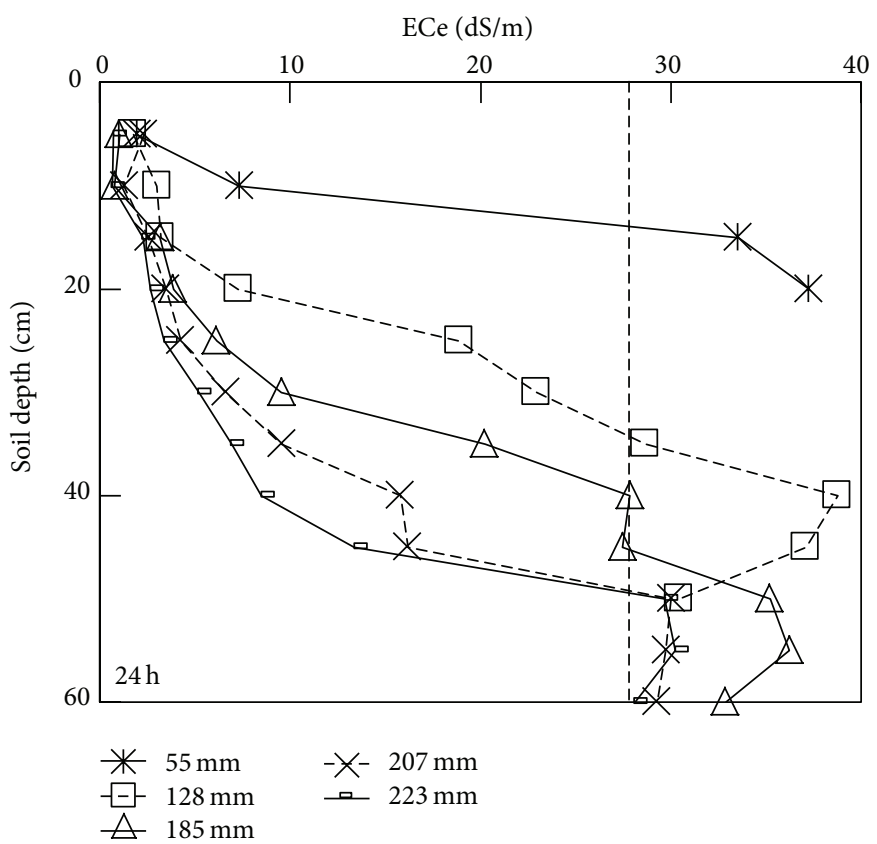

(b)

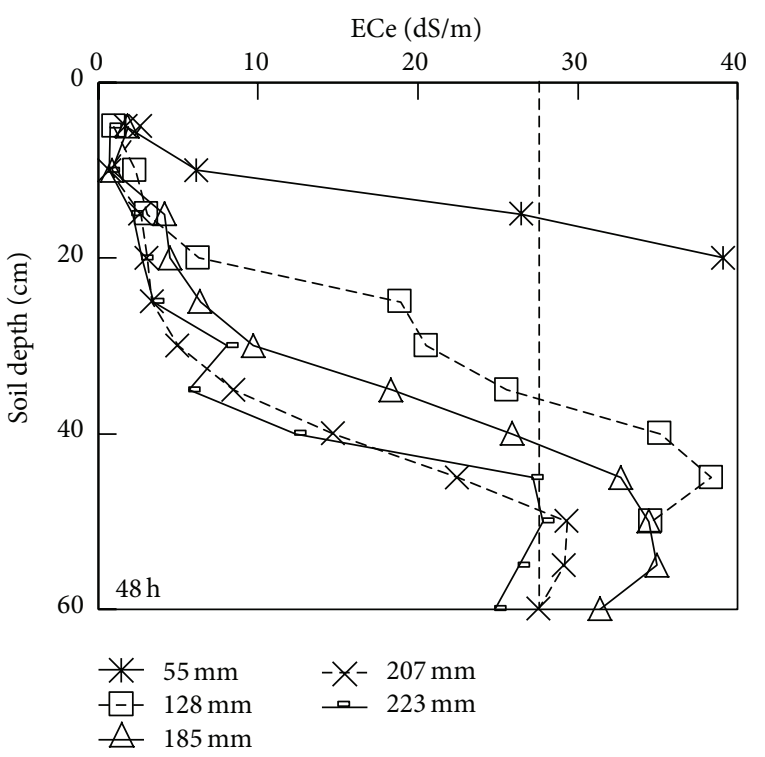

(c)

FIgURE 3: The depth distributions of ECe at 0 hour (a), 24 hours (b), and 48 hours (c) during water redistribution under different water amounts applied.

the treatments increased gradually with an increase in the soil depth.

As the irrigation amount increased, the depth of the highest SAR also increased. For the irrigation amounts of $55,128,185,207$, and $223 \mathrm{~mm}$, the zone with the maximum SAR was located at a depth of 10-15, 35-40, 50-55, 50-55, and $55-60 \mathrm{~cm}$, and the corresponding SAR was 387.2, 481.0, $532.6,489.8$, and $450.3(\mathrm{mmol} / \mathrm{L})^{0.5}$, respectively. However, except for the irrigation amount of $55 \mathrm{~mm}$, a low SAR zone $(\mathrm{SAR}<15 \mathrm{mmol} / \mathrm{L})^{0.5}$ was observed at a depth of $0-$ $5 \mathrm{~cm}$. For the other four irrigation amounts, a low $S A R$ zone also was observed at a depth of $0-10 \mathrm{~cm}$. Meanwhile, as the irrigation amount increased, the SAR value of each depth increased, the amplitude of variation increased, and the depth increased, except for the irrigation amounts of 207 and $223 \mathrm{~mm}$. The average soil SAR in the entire profile changed as the experiment progressed. For the irrigation amount of $55 \mathrm{~mm}$, the average soil SAR at a depth of 0$20 \mathrm{~cm}$ increased by $272.1 \%$, while that of the other irrigation amounts decreased. A significant reduction in the soil SAR occurred at a depth of $0-20 \mathrm{~cm}$ for the irrigation amounts of $128,185,207$, and $223 \mathrm{~mm}$. Compared to the initial levels, 


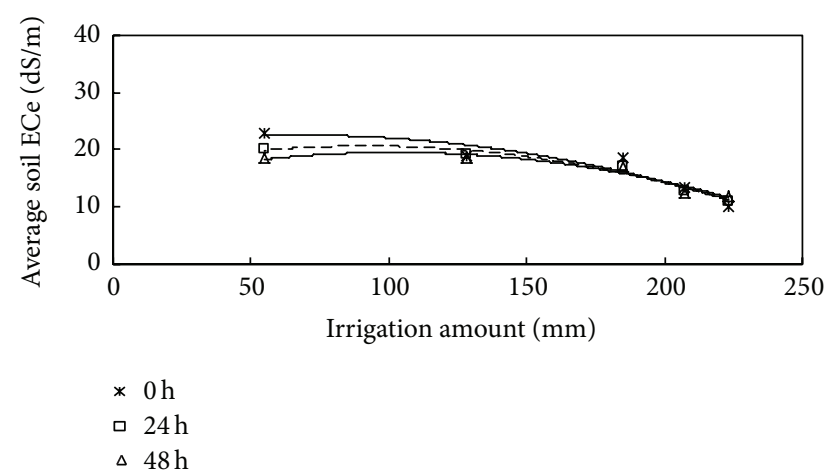

FIGURE 4: Relationships between average ECe in wetted zone and irrigation amount.

the SAR at $0-20 \mathrm{~cm}$ was decreased by $61.3 \%, 70.4 \%, 79.2 \%$, and $79.3 \%$, respectively. However, the average SAR at $20-40$ and $40-60 \mathrm{~cm}$ increased, and the greatest increase occurred at a depth of 40-60 cm. At this depth, the observed increase was more than two times greater than that of the initial value for all four irrigation amounts.

3.5. Depth Distribution of Soil pH. The depth distributions of $\mathrm{pH}$ at $0 \mathrm{~h}, 24 \mathrm{~h}$, and $48 \mathrm{~h}$ during water redistribution are shown in Figures 6(a), 6(b), and 6(c), respectively. Changes in the soil $\mathrm{pH}$ associated to salt leaching were determined in each irrigation amount. Due to changes in the ECe depth distributions, the profiles of the soil $\mathrm{pH}$ in the experimental column changed concomitantly, but the amplitude of its variation was small. For all five irrigation amounts, high soil $\mathrm{pH}$ zones were primarily observed in the $0-10 \mathrm{~cm}$ layer at the end of irrigation. Moreover, the $\mathrm{pH}$ values of profiles obtained for irrigation amounts of 207 and $223 \mathrm{~mm}$ were higher than those for 55, 128, and $185 \mathrm{~mm}$. Compared to the initial soil pH, the average $\mathrm{pH}$ values of the entire wet zone for the irrigation amounts of 55, 128, 185, 207, and $223 \mathrm{~mm}$ were increased by $2.9 \%, 6.2 \%, 5.7 \%, 6.3 \%$, and $6.5 \%$, respectively. Thus, as the irrigation amount increased, the average soil $\mathrm{pH}$ also increased, and the irrigation amount of $55 \mathrm{~mm}$ significantly differed from each of the other four irrigation amounts.

During soil water redistribution, the layer with high soil $\mathrm{pH}$ expanded for each water dose, but the observed differences among successive sampling times in the period of water redistribution were minor. These results indicated that the irrigation amount played an important role in the salt concentration of the soil but had a weaker effect on the average soil $\mathrm{pH}$.

The study focused on the influence of irrigation amounts with microsprinkler irrigation on water, salt, and $\mathrm{pH}$ profiles in a coastal saline soil under laboratory conditions. Therefore the outcome of the experiment performed may be affected by some uncertainties. To adapt to the local conditions in northern China, further studies in field should be considered.

\section{Conclusions}

The irrigation amount, which ranged from 55 to $223 \mathrm{~mm}$, had a significant effect on the depth distributions of $\theta$,

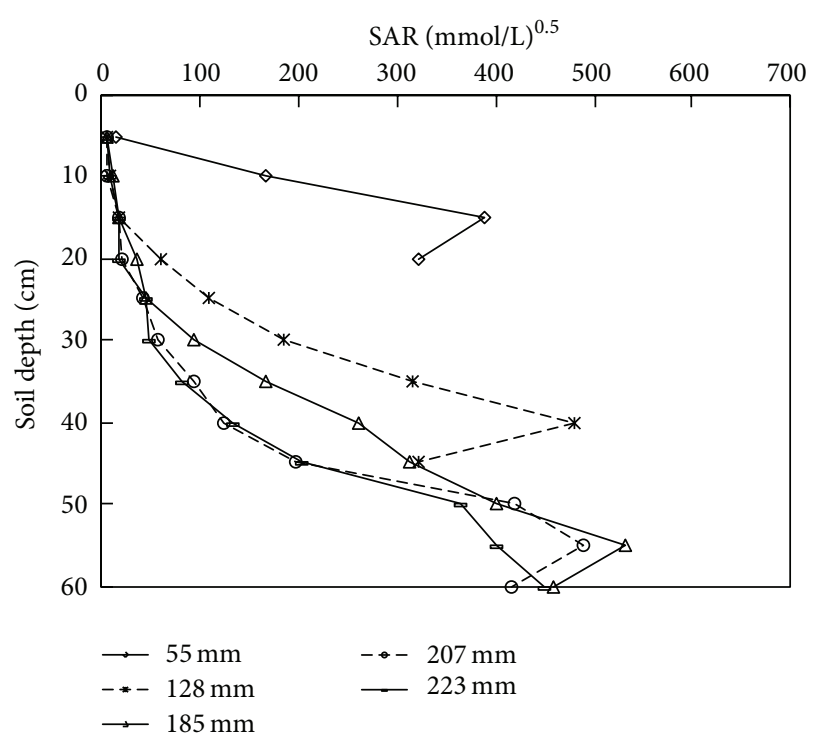

FIgURE 5: The depth distributions of SAR at 0 hour, just after irrigation has finished, under different water amounts applied.

ECe, and SAR but had a relatively minor impact on the depth distributions of $\mathrm{pH}$. Due to the characteristics of the studied soil, mainly the high clay content and low hydraulic conductivity, significant differences between the periods of water redistribution were not observed.

The differences among the depth distributions of $\theta$ were significant for the irrigation amounts of 55,128 , and 185 , but not for those of 207 and $223 \mathrm{~mm}$.

Except for the irrigation amount of $55 \mathrm{~mm}$, salt was leached from the soil, and the low salinity zone enlarged as the irrigation amount increased. Parabolic relationship between the average ECe of the wetting front and the irrigation amounts was observed at 0,24 , and $48 \mathrm{~h}$ during water redistribution. Moreover, the reduction in the average ECe ranged from $17.6 \%$ for the irrigation amount of $55 \mathrm{~mm}$ to $63.7 \%$ for the $223 \mathrm{~mm}$ treatment.

The depth distributions of the SAR were similar to those of the ECe, but the observed reduction was smaller than that of the ECe.

Taking all of the above factors into consideration, irrigation amounts of $207 \mathrm{~mm}$ for $50-60 \mathrm{~cm}$ soil depth under microsprinkler irrigation appear to be the best option to reclaim highly saline coastal land surrounding Bohai Gulf in northern China.

\section{Conflict of Interests}

The authors declare that there is no conflict of interests regarding the publication of this paper.

\section{Acknowledgments}

This study was supported by the National High Technology R\&D Program of China (Grant nos. 2013 BAC02B02 and 


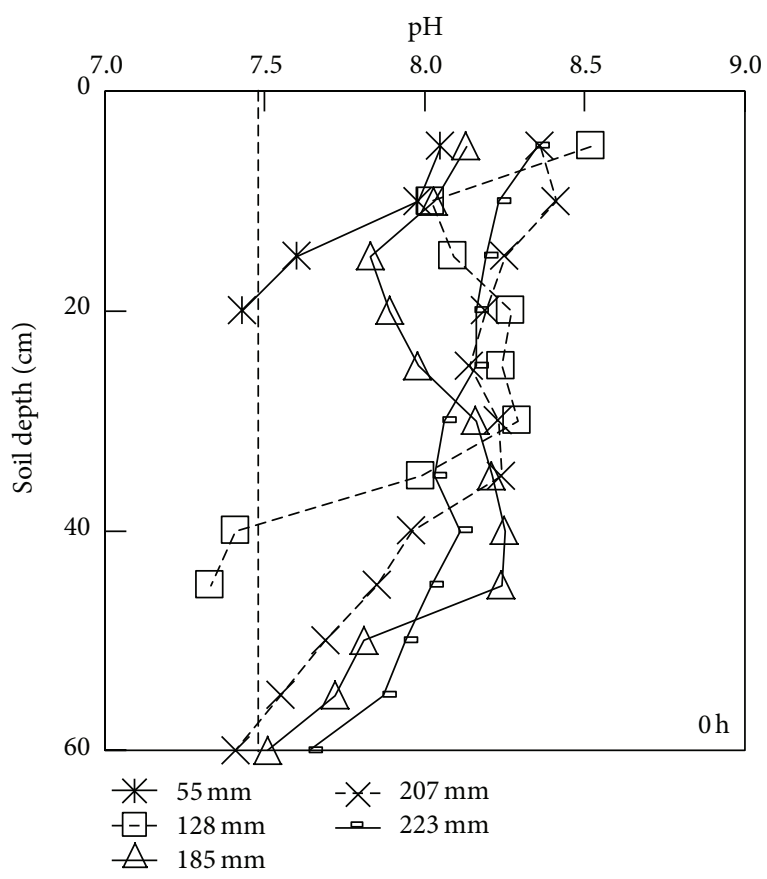

(a)

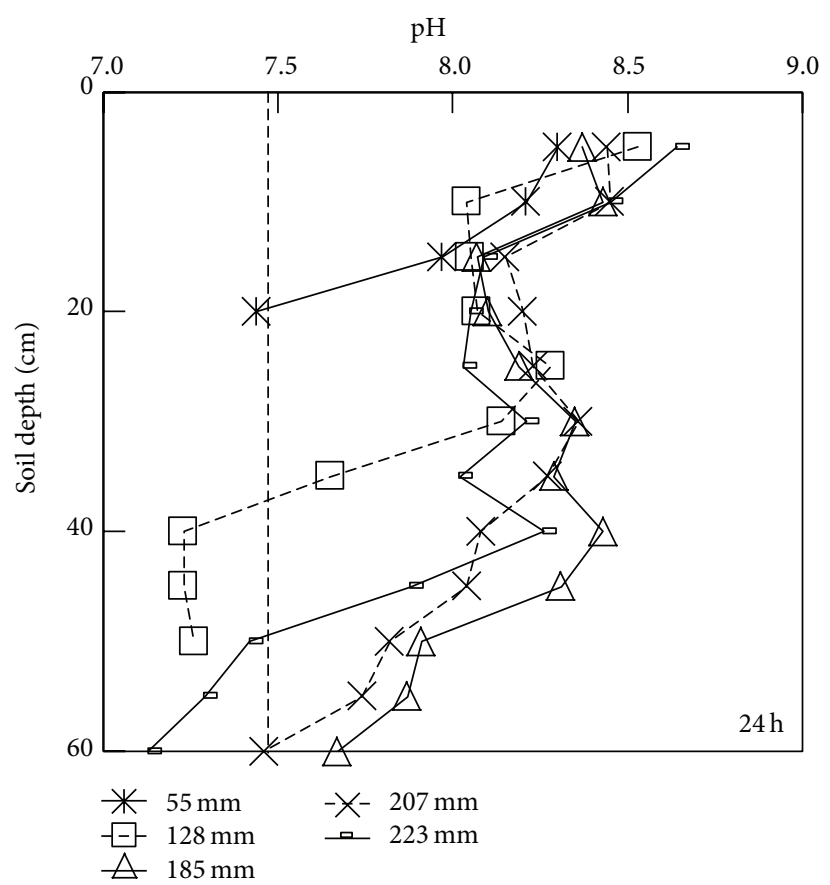

(b)

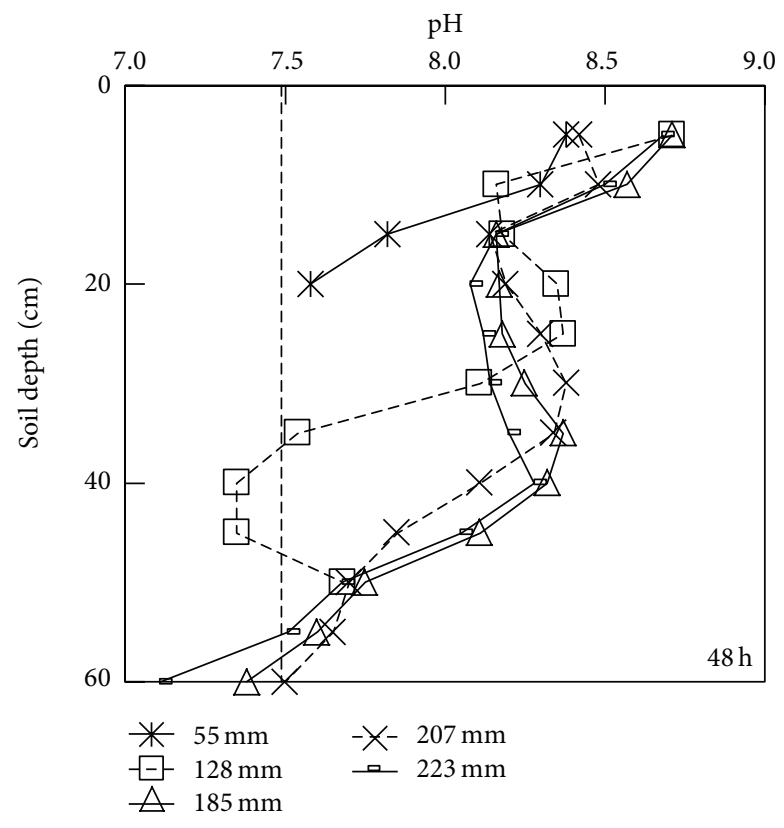

(c)

FIGURE 6: The depth distributions of $\mathrm{pH}$ at 0 hour (a), 24 hour (b), and 48 hours (c) during water redistribution under different water amounts applied.

2013BAC02B01), the Priority Academic Program Development of Jiangsu Higher Education Institutions (1033000001), the Research Foundation for Advanced Talents of Jiangsu University (1281440009), the Knowledge Innovation Program of the Chinese Academy of Sciences (Grant no. KZCX 2-YW-359), and the Action Plan for Development of Western China of Chinese Academy of Sciences (Grant no. KZCX 2XB3-16).

\section{References}

[1] Z. Shi, Y. Li, R. C. Wang, and F. Makeschine, "Assessment of temporal and spatial variability of soil salinity in a coastal saline field," Environmental Geology, vol. 48, no. 2, pp. 171-178, 2005.

[2] X. Wang, Q. Zhao, Y. Hu et al., "An alternative water source and combined agronomic practices for cotton irrigation in coastal saline soils," Irrigation Science, vol. 30, no. 3, pp. 221-232, 2012. 
[3] J. Sun, Y. Kang, S. Wan, W. Hu, S. Jiang, and T. Zhang, "Soil salinity management with drip irrigation and its effects on soil hydraulic properties in north China coastal saline soils," Agricultural Water Management, vol. 115, pp. 10-19, 2012.

[4] Z. Q. Wang, S. Q. Zhu, R. P. Yu et al., China Saline and Sodic Soils, Science Press, Beijing, China, 1993, edited by P.L. Chen.

[5] M. He, K. Sakurai, G. Q. Wang, Z. H. Chen, Y. Shu, and J. J. Xu, "Physico-chemical characteristics of the soils developed from alluvial deposits on Chongming Island in Shanghai, China," Soil Science and Plant Nutrition, vol. 49, no. 2, pp. 223-229, 2003.

[6] H. R. Khan, I. U. Ahmed, and H. P. Blume, "Effects of gypsum and $\mathrm{Zn}$ on uptake ratios of $\mathrm{Na}, \mathrm{K}$ and growth-yield of rice grown on a coastal saline soil," Zeitschrift fur Pflanzenernahrung und Bodenkunde, vol. 159, no. 4, pp. 351-356, 1996.

[7] Z. Shi, M. X. Huang, and Y. Li, "Physico-chemical properties and laboratory hyperspectral reflectance of coastal saline soil in Shangyu City of Zhejiang Province, China," Pedosphere, vol. 13, no. 3, pp. 193-198, 2003.

[8] M. Singh, A. K. Bhattacharya, T. V. R. Nair, and A. K. Singh, "Ammonium losses through subsurface drainage effluent from rice fields of coastal saline sodic clay soils," Water, Air, and Soil Pollution, vol. 127, no. 1-4, pp. 1-14, 2001.

[9] A. Datta, J. B. Yeluripati, D. R. Nayak, K. R. Mahata, S. C. Santra, and T. K. Adhya, "Seasonal variation of methane flux from coastal saline rice field with the application of different organic manures," Atmospheric Environment, vol. 66, pp. 114-122, 2013.

[10] F. S. Davies and D. Wilcox, "Waterlogging of containerized rabbiteye blueberries in Florida," Journal of the American Society for Horticultural Science, vol. 109, pp. 520-524, 1984.

[11] D. R. Bryla and R. G. Linderman, "Implications of irrigation method and amount of water application on Phytophthora and Pythium infection and severity of root rot in highbush blueberry," HortScience, vol. 42, no. 6, pp. 1463-1467, 2007.

[12] A. Kumar and I. P. Abrol, "Studies on the reclaiming effect of Karnal-grass and para-grass grown in a highly sodic soil," Indian Journal of Agricultural Sciences, vol. 54, pp. 189-193, 1984.

[13] N. Ahmad, R. H. Qureshi, and M. Qadir, "Amelioration of a calcareous saline-sodic soil by gypsum and forage plants," Land Degradation \& Rehabilitation, vol. 2, no. 4, pp. 277-284, 1990.

[14] T. Zhang, Y. Kang, and S. Wan, "Shallow sand-filled niches beneath drip emitters made reclamation of an impermeable saline-sodic soil possible while cropping with Lycium barbarum L.," Agricultural Water Management, vol. 119, pp. 54-64, 2013.

[15] J. X. Sun, Y. H. Kang, and S. Q. Wan, "Effects of an imbedded gravel-sand layer on reclamation of coastal saline soils under drip irrigation and on plant growth," Agricultural Water Management, vol. 123, pp. 12-19, 2013.

[16] D. Nielsen, J. W. Biggar, and J. N. Luthin, "Desalinization of soils under controlled unsaturated flow conditions," in Proceedings of the 6th International Congress on Irrigation and Drainage, pp. 15-19, New Delhi, India, 1966.

[17] J. D. Oster, L. S. Willardson, and G. J. Hoffman, "Sprinkling and ponding techniques for reclaiming saline soils," Transactions of the American Society of Agricultural Engineers, vol. 16, no. 1, pp. 89-91, 1973.

[18] S. Zeqiang, Research on the Effect of Sprinkler Irrigation on Soil Structure and the Characteristic of Water and Nitrogen Distribution, Graduate University of Chinese Academy of Sciences Press, Beijing, China, 2006.

[19] D. Reich, R. Godin, and I. Broner, Micro-Sprinkler Irrigation for Orchards, Colorado State University Extension, Crop Series, Irrigation, 2009, http://www.ext.colostate.edu/.

[20] I. Troiano, C. Garretson, C. Krauter, J. Brownell, and J. Huston, "Brownell influence of amount and method of irrigation water application on leaching of atraziue," Hournal of Environmental Quality, vol. 22, pp. 290-298, 1993. 

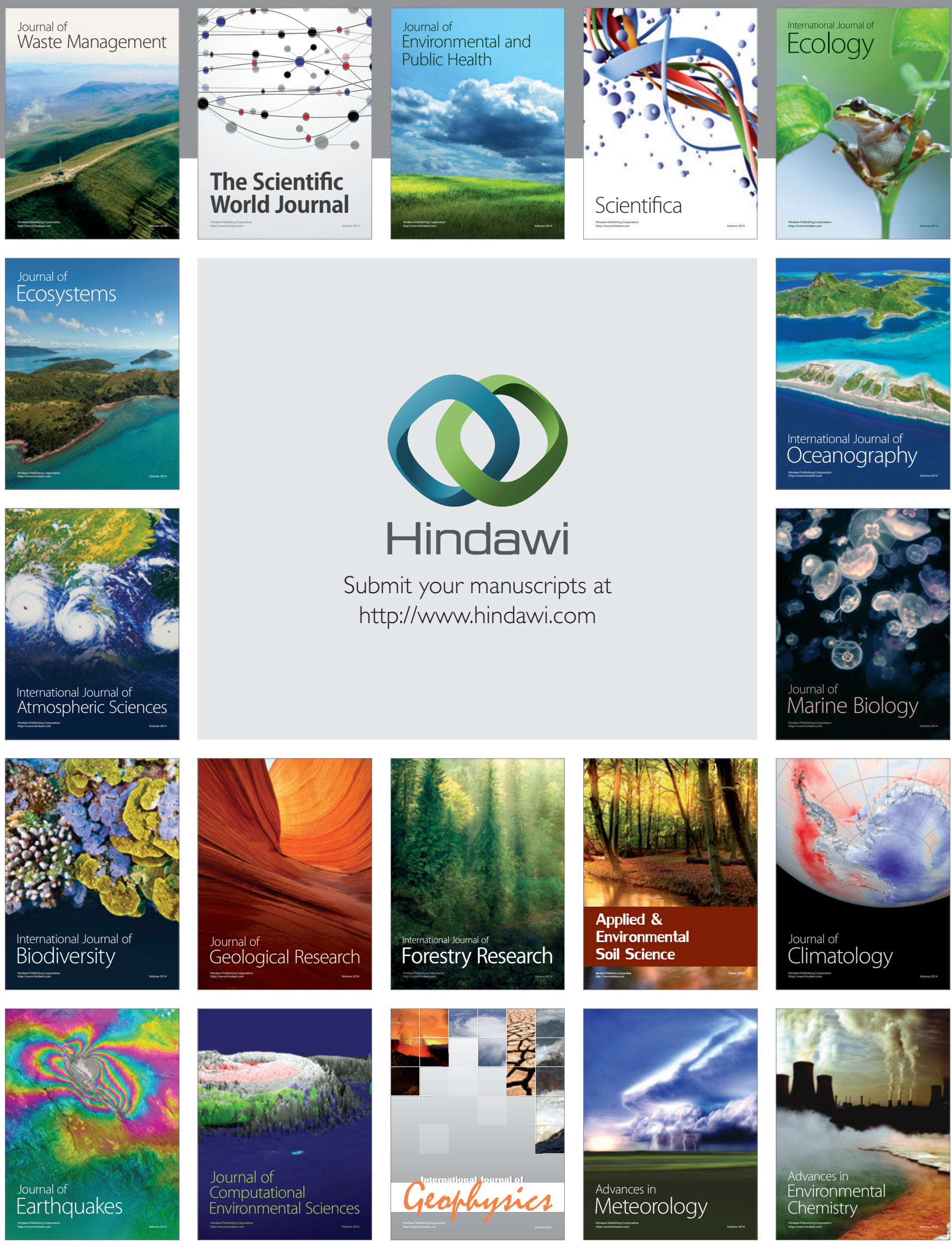